\section{Amazonian Indians and the forest environment}

SIR - The statement in a recent News and Views article by May $^{1}$ that Amazonian Indians possess a much greater knowledge of their environment than has been commonly believed prompts me to communicate some data gathered recently that further support this contention.

The Institute of Economic Botany of The New York Botanical Garden (supported by E. J. Noble Foundation) is engaged in a four-year comparative ethnobotanical study on the question "How important is the forest to Amazonian Indians?" Much has been written on the significance of the forest to Amazonian Indians ${ }^{2}$, but rarely has the degree of importance been quantified, and then only on a very small scale $^{3}$. A primary goal of the project is to quantify forest utilization for 1 hectare of forest with each tribe studied.

The Chacobo Indians of Bolivia were the first to be studied ${ }^{4}$. Just 30 years ago, the tribe numbered only about 135 individuals who essentially lived outside the Bolivian cash economy by hunting, fishing, and subsistence agriculture in isolated forest locations along the Ríos Ivon, Benicito, Geneshuaya and Yata in the northeastern Bolivian department of Beni ${ }^{5-7}$. In 1955, modern missionary work with the Chacobo began and in the ensuing years a number of aspects of their culture, including their ceremonies, traditional mode of dress, and supernatural beliefs have been lost. Other aspects, including their botanical knowledge, are to a greater degree intact, at least among the elders. Although their numbers have increased to about 400 , their culture is on the verge of extinction. The majority of the tribe (some 280 individuals) live today on 43,000 hectares of forested land along the Río Ivon, and on this reserve make their capital village, Alto Ivon $\left(11^{\circ} 45^{\prime} \mathrm{S}, 66^{\circ} 02^{\prime} \mathrm{W}\right)$. The vegetation around Alto Ivon is Tropical Moist, terra firme forest. The elevation is about $200 \mathrm{~m}$ and the topography is level. The inventory, which was carried out in January and February 1984, was made on a strip of undisturbed forest $10 \times 1,000 \mathrm{~m}$. Every tree with a DBH (diameter at breast height) of $10 \mathrm{~cm}$ or more was marked and collected. Indigenous names and use information were obtained from Chacoba informants.

The inventory showed that 91 species, represented by 649 individual trees, occurred in the hectare. Of these, the Chacobo had uses for 75 species $(82 \%$ of the total), or 619 individual trees ( $95 \%$ of the total). The species were grouped into five classes of utilization: food, fuel, crafts and construction, medicinal, and commercial. Some species, especially the palms, had uses in more than one category. There was only one commercially exploited species, wild rubber (Hevea brasiliensis), and 5 individuals of that species were found. Fourteen species (163 individuals) were used specifically as a fuel for cooking, smoking rubber, or both. Thirty-three species of trees (264 individuals) provided edible wild fruits. Twenty-three species ( 225 individuals) were collected that were used in crafts and construction. Finally, 23 species of trees (271 individuals) were found in the sample hectare that were used by the Chacobo for medicinal purposes.

The demonstration that the Chacoba utilize $82 \%$ of the tree species in their environment has significant implications not only for the thesis that such tribes have a profound knowlege of their forest, but also for those individuals concerned with the protection of indigenous cultures in Amazonia. For example, by combining this sort of ethnoecological information with the data being obtained from the Minimal Critical Size of Ecosystems Project (cosponsored by the Brazilian National Institute for Amazon Research and the World Wildlife Fund-US) ${ }^{8}$, it should be possible to make more intelligent recommendations as to how much forested land must be allocated for self-sustaining Indian reserves.

Every ethnobotanical study done in Amazonia reaffirms the view that indigenous peoples are scientifically interesting, legitimate and invaluable sources of knowledge about the forest. Since one tribe differs from another in important ways, and since these people are so rapidly losing their traditional knowledge, many more studies are urgently needed. It is clear that botanical inventory involving indigenous cultures, especially in the tropics, can quite justifiably be considered the most worthwhile expenditure of time and effort for this generation of field botanists.

BRIAN M. BOOM

The New York Botanical Garden,

Bronx,

New York 10458, USA

I. May, R.M. Nature 312, 19-20 (1984)

2. Lévi-Strauss, C. in Handbook of South American Indians Vod.3, (ed. J.H. Steward) 465-486 (Smithsonjan, Washington, 1950)

3. Carneiro, R.L. in The Nature and Status of Ethnobotany (ed. R.I. Ford) 201-216 (Univ. of Michigan, Ann Arbor, 1978). Webster, B. New York Times, Sunday, November 4, 1984. 5. Métraux A in Handbook of South American Indians $V 013$, 6. Prost M.D. Costumbres Habilidedes y Cuadro de la Vido Humana Entre los Chacobos (Instituto Lingüistico de Verano, Riberalta, Bolivia, 1970)

7. Torrico, P.B. Indígenas en el Corazón de América (Los Amigos del Libro, La Paz, Bolivia, 1971).

8. Lewin, R. Science 225, 611-612 (1984).

\section{Electrical aspects of the snowflake crystal}

SIR - The discussion "No pattern yet for snowflakes" laments the inability of Vicsek's calculations ${ }^{2}$ to reproduce the long-range symmetry observed in snowflakes. In the closing lines it is suggested that adding lattice vibrations to the calculations may be helpful. Because snowflakes are polycrystalline conglomerates there would seem to be little chance that these very short wavelength vibrations could be the mediating phenomenon for symmetry patterns that are many millimetres in size. Long wavelength vibrations have been proposed by McLachlan ${ }^{3}$ and later by Tolansky ${ }^{4}$. An inherent drawback in any vibrational theory is that the details of the observed structure must be matched by a spectrum of vibrations with equivalent complexity in amplitude, frequency, and phase. In addition, a mechanism for the generation, transmission, and maintenance of these vibrations must be found.

A simpler, more direct mechanism is desirable to explain the generation of the observed cooperative behaviour in dendrite growth. I have proposed a mechanism that will provide the long-range symmetry observed based on phenomena known to be present during the snowflake development ${ }^{5}$. The fact that snowflakes carry an electric charge has been observed by many workers in the field. The influence of electrical fields on ice crystal growth has been observed by Zawidzki and Papée ${ }^{6}$, as well as by Muchnik and Rud'ko in the Soviet Union. The mechanism of symmetry induction is the accretion of water vapour at those sites on the crystall that lead to the lowest potential-energy state. There are twelve symmetry axes to the common snowflake. The axis of each dendrite and the bisector of the angle between dendrites serve as reflection planes to sequentially propagate the pattern to all dendrites. Pohl has described the behaviour of dielectric materials in divergent fields and its commerical application?

It is interesting to note that this symmetry-inducing mechanism operates regardless of the sign of the charge of the snowflake, which may change during the growth period, or whether the snowflake is increasing or diminishing in size. It is also independent of the number of dendrites, or their length or configuration.

An examination of a collection of photographs of snowflakes, such as that of Nakaya ${ }^{8}$, leaves one impressed by the varieties of type and detail of the symmetry achieved in snowflakes.

It would be most interesting if future calculational models of snowflake growth would include the influence of their external electrical field. Crystal growth from the liquid phase will not show phenomena dependent on an external electrical field and thus cannot duplicate the symmetry found in snowflakes. It is interesting to note that this restriction would not necessarily apply if vibrational processes were the source of symmetry.

ROALD A. SCHRACK

National Bureau of Standards,

Gaithersburg,

Maryland 20899, USA

1. Maddox, J. Nature 313, 93 (1985)

2. Vicesk, T Phys, Rev, Lett. 53, 2281 (1984).

. McLachlan, Proc natn. Acad. Sci: U.S.A. 43, 143 (1957).

Tolansky Noture 181, 256 (1958)

J. Wash, Acad Sci 48, 273 (1958).

Zawdski \& Papée Nature 196, 568 (1962).

Pohl J. appl. Phys. 22, 869 (1951); 29, 1182 (1958).

8. Nakaya, U. Snow Crystals, Natural and Artificial (Harvard University Press, 1954) 